\title{
Bias correction of daily GCM rainfall for crop simulation studies
}

\author{
Amor V.M. Ines ${ }^{1}$, James W. Hansen * \\ International Research Institute for Climate Prediction, The Earth Institute at Columbia University, Palisades, NY 10964, USA
}

Received 27 September 2005; accepted 24 March 2006

\begin{abstract}
General circulation models (GCMs), used to predict rainfall at a seasonal lead-time, tend to simulate too many rainfall events of too low intensity relative to individual stations within a GCM grid cell. Even if bias in total rainfall is corrected relative to a target location, this distortion of frequency and intensity is expected to adversely affect simulations of crop growth and yield. We present a procedure that calibrates both the frequency and the intensity distribution of daily GCM rainfall relative to a target station, and demonstrate its application to maize yield simulation at a location in semi-arid Kenya. If GCM rainfall frequency is greater than observed frequency for a given month, averaged across years, GCM rainfall frequency is corrected by discarding rainfall events below a calibrated threshold. To correct the intensity distribution, each GCM rainfall amount above the calibrated threshold is mapped from the GCM intensity distribution onto the observed distribution. We used a gamma distribution for observed rainfall intensity, and considered both gamma and empirical distributions for GCM rainfall intensity. At the study location, the proposed correction procedure corrected both the mean and variance of monthly and seasonal GCM rainfall total, frequency and mean intensity. The empirical (GCM)-gamma (observed) transformation overestimated mean intensity slightly. A simple multiplicative shift did a better job of correcting monthly and seasonal rainfall totals, but left substantial frequency and intensity bias. All of the bias correction procedures improved maize yield simulations, but resulted in substantial negative mean bias. This bias appears to be associated with a tendency for the GCM rainfall to be more strongly autocorrelated than observed rainfall, resulting in unrealistically long dry spells during the growing season. Nonlinearity of crop response to the variability of water availability across GCM realizations may also contribute. Averaging simulated yields each year across multiple GCM realizations improved yield predictions. The proposed correction procedure provides an option for using the daily output of dynamic climate prediction models for impact studies in a manner that preserves any useful predictive information about the timing of rainfall within the season. However, its practical utility for yield forecasting at a long lead-time may be limited by the ability of GCMs to simulate rainfall with a realistic time structure.
\end{abstract}

(C) 2006 Elsevier B.V. All rights reserved.

Keywords: General circulation model (GCM); Crop simulation model; Precipitation; Corn (Zea mays); Seasonal climate prediction

\section{Introduction}

Seasonal climate prediction offers the potential to anticipate variations in crop production early enough to

\footnotetext{
* Corresponding author. Tel.: +1 845680 4410/4501; fax: +18456804864 .

E-mail addresses: ines@iri.columbia.edu, avmines@tamu.edu (Amor V.M. Ines), jhansen @iri.columbia.edu (J.W. Hansen).

${ }^{1}$ Present address: Department of Biological and Agricultural Engineering, Texas A\&M University, College Station, TX 77843, USA.
}

adjust critical decisions. Operational seasonal forecasts are typically expressed as seasonal (e.g., 3-month) mean anomalies, averaged in space. Crop production is not a simple function of seasonal mean climatic conditions, but a function of dynamic, nonlinear interactions between weather, soil water and nutrient dynamics, and physiology and phenology of the crop. Weathersensitive, process-oriented crop simulation models typically simulate these interactions on a daily time step. Atmospheric general circulation models (GCMs) used for seasonal forecasting simulate a full set of 
meteorological variables at a sub-daily time step. However, imperfect model specification and spatial averaging within GCM grid cells distorts day-to-day variability. The distortion includes a tendency to generate too many rainfall events, with intensities that are too low relative to individual stations within the GCM grid cell (Carter et al., 1994; Mearns et al., 1990, 1995; Goddard et al., 2001). Even if biases in total rainfall are corrected relative to a target location, this distortion of frequency and intensity is expected to adversely affect simulations of crop growth and yield (Mearns et al., 1996; Riha et al., 1996; Hansen and Jones, 2000; Baron et al., 2005).

Statistical and dynamic downscaling methods are available to correct GCM predictions relative to climatology at a local, sub-grid scale (e.g., Wilby and Wigley, 1997; Wilby et al., 1998; Wood et al., 2002). Statistical downscaling approaches are generally applied to aggregate rather than daily time scales. When they are applied at a daily time scale, the perfect prognosis assumption required makes them quite susceptible to GCM biases. One approach to addressing the problem of distortion of daily variability is to aggregate GCM predictions into seasonal or subseasonal (e.g., monthly) means, then use a stochastic weather model to disaggregate in time to produce synthetic daily weather that is conditioned on the predictions (Wilks, 2002; Hansen and Ines, 2005; Feddersen and Andersen, 2005).

A few studies have used daily GCM outputs directly for crop simulation studies. Mavromatis and Jones (1999) used daily outputs from the HadCM2 GCM as input to CERES-Wheat for studying potential impacts of climate change on regional winter wheat production in France. Yields simulated with GCM weather data approximated mean yields simulated with observed weather during the past century, and captured a yield trend associated with the recent trend in observed temperature. They concluded, however, that daily GCM outputs were not useful for estimating future agricultural risk because they did not represent year-toyear variability adequately. Challinor et al. (2005) have also explored the use of daily GCM outputs for forecasting groundnut yields in western India. Because of GCM biases, the crop model required calibration to observed district yields in order to obtain good predictions.

In this paper, we present a technique for correcting the biases of both the frequency and the intensity distribution of daily GCM rainfall relative to a target station. The procedure involves mapping of distributions between the grid-based GCM data and observed data at a given location. We demonstrate its application to maize yield simulation at a location in semi-arid Kenya. Although our approach is motivated by interest in translating GCM-based seasonal climate forecasts into forecasts of crop response, it may be relevant to other applications of seasonal climate forecasts that require daily meteorological variables.

\section{Methods}

\subsection{Simultaneous frequency and intensity correction}

Mean rainfall $\bar{X}_{\mathrm{m}}\left(\mathrm{mm} \mathrm{d}^{-1}\right)$ in calendar month $m$ is the product of mean intensity, $\mu_{\mathrm{I}}\left(\mathrm{mm} \mathrm{wd}^{-1}\right)$ (" $\mathrm{wd}^{\prime}$ " is wet day, with $\geq 0.1 \mathrm{~mm}$ rain) and relative frequency, $\pi$ $\left(\mathrm{wd} \mathrm{d}^{-1}\right.$ ). Therefore correcting any bias of the two rainfall components will also correct the monthly total rainfall itself. We propose a two-step bias correction procedure that adjusts GCM rainfall to approximate the long-term frequency and intensity distribution observed at a given station. The correction involves truncating the GCM rainfall distribution at a point that approximately reproduces the long-term observed relative frequency of rainfall, then mapping the truncated GCM rainfall intensity distribution onto a gamma distribution fitted to observed intensity distribution. These methods for truncating distributions and mapping one distribution onto another are well established in probabilistic modeling (e.g., Law and Kelton, 1982). The distribution mapping approach has been used to correct bias of monthly GCM precipitation (Wood et al., 2002) but, to the best of our knowledge, has not been applied to correct daily GCM rainfall relative to a given station. For convenience, and consistency with the convention of updating GCM forecasts monthly, we apply the calibration for each of the 12 calendar months.

\subsubsection{Correcting rainfall frequency}

We correct the frequency of daily GCM rainfall by fitting a threshold value $\tilde{x}_{G C M}$ to truncate the empirical distribution of the raw daily GCM rainfall, such that the mean frequency of rainfall above the threshold matches the observed mean rainfall frequency. The threshold is calculated from the empirical observed and GCM cumulative rainfall distribution as,

$\tilde{x}_{\mathrm{GCM}}=F_{\mathrm{GCM}}^{-1}\left(F_{\mathrm{obs}}(\tilde{x})\right)$,

where $F(\cdot)$ and $F^{-1}(\cdot)$ denote a cumulative distribution function (CDF) and its inverse, and subscripts indicate 
GCM or observed daily rainfall. In this case, the minimum observed rainfall amount $\tilde{x}$ for a day to be considered wet was $0.1 \mathrm{~mm}$. The empirical CDF $F\left(x_{i}\right)$, on day $i$, is obtained simply as the relative position of $x_{i}$ within a sorted array of long-term daily rainfall data for a given month.

\subsubsection{Correcting rainfall intensity}

We corrected the GCM intensity distribution $F_{\mathrm{I}, \mathrm{GCM}}(x)$ (i.e., the $\mathrm{CDF}$ of daily rainfall amounts above calibrated threshold $\tilde{x}_{\mathrm{GCM}}$ ) by mapping it onto the observed intensity distribution $F_{\mathrm{I}, \mathrm{obs}}(x)$. We apply this correction separately for each of the 12 calendar months. Corrected GCM rainfall $x^{\prime}$ on day $i$ is calculated as,

$x_{i}^{\prime}= \begin{cases}F_{\mathrm{I}, \mathrm{obs}}^{-1}\left(F_{\mathrm{I}, \mathrm{GCM}}\left(x_{i}\right)\right), & x_{i} \geq \tilde{x} \\ 0 & x_{i}<\tilde{x}\end{cases}$

The transformation in Eq. (1) is equivalent to transforming an observation sampled from the GCM rainfall intensity distribution to a 0.1 uniform distribution (the definition of a CDF), then transforming the sampled uniform deviate into the observed rainfall intensity distribution by taking the inverse of it's CDF. The CDFs can be either empirical (i.e., sorted arrays of observations) or fitted to some theoretical distribution. The two-parameter gamma distribution is frequently used to model the intensity distribution of observed rainfall. Although it does not represent rainfall as well as the more flexible, three-parameter hyper-exponential distribution, we selected the gamma because it has a closed analytical form that can be readily inverted. There is less experience with the distribution of rainfall intensities produced by dynamic climate models. Because of uncertainty about the gamma distribution's suitability for modeling GCM rainfall intensities, we considered both an empirical and a gamma distribution to represent GCM rainfall above the fitted threshold. We only considered the gamma distribution to represent observed rainfall intensities. This resulted in two variations of the intensity distribution calibration Eq. (2): (a) a transformation from a gamma fitted to the GCM intensities to a gamma fitted to the observed intensities (denoted GG), and (b) a transformation from the empirical GCM intensity distribution to a gamma fitted to the observed intensities (denoted EG).

For the GG transformation, first, we fitted the truncated daily GCM rainfall and historical rainfall data to a two-parameter gamma distribution Eq. (3); see Law and Kelton, 1982), and then we mapped the CDF Eq. (4) of the truncated daily GCM rainfall to the CDF of the truncated historical data.

$F(x ; \alpha, \beta)=\frac{1}{\beta^{\alpha} \Gamma(\alpha)} x^{\alpha-1} \exp \left(-\frac{x}{\beta}\right) ; \quad x \geq \tilde{x}$

$F(x ; \alpha, \beta)=\int_{\tilde{x}}^{x} f(t) \mathrm{d} t$

The shape, $\alpha$, and scale parameters, $\beta$, for each gamma distribution are determined using Maximum Likelihood Estimation. The corrected GCM rainfall amount for that day can be calculated by substituting the fitted gamma CDFs into Eq. (2). For the EG transformation, the procedure is the same as above; only, an empirical distribution is assumed to describe the truncated daily GCM rainfall.

\subsection{Correcting monthly rainfall by a multiplicative shift}

For comparison, we included a simple multiplicative shift to correct the bias of the mean monthly GCM rainfall:

$x_{i}^{\prime}=x_{i} \frac{\bar{X}_{\mathrm{obs}}}{\bar{X}_{\mathrm{GCM}}}$,

where $x_{i}$ and $x_{i}^{\prime}$ again refer to raw and corrected GCM rainfall on day $i$, and $\bar{X}_{\mathrm{GCM}}$ and $\bar{X}_{\mathrm{obs}}$ are long-term monthly mean rainfall from the GCM and observations for a given month. This procedure adjusts only rainfall intensity to reproduce the long-term mean observed monthly rainfall, and therefore does not correct any systematic error in frequency or the intensity distribution.

\subsection{Data}

The analyses are based on data from the Katumani Dryland Research Center $\left(1^{\circ} 35^{\prime} \mathrm{S}, 37^{\circ} 14^{\prime}\right.$ E, 1601 a.m.s.l) in the Machakos District of semi-arid eastern Kenya. Rainfall has a bimodal distribution. The climate is marginal for maize in both seasons, yet because of strong food preferences, maize remains the dominant staple crop. The October-December "short rains" is the more important maize growing season, and is fairly predictable at a seasonal lead-time using statistical (Indeje et al., 2000; Mutai et al., 1998) and dynamic (Hansen and Indeje, 2004) forecast models. Our study benefits from previous crop model-based research at the Katumani site (Probert, 1992; Keating et al., 1993). 
We used daily rainfall observations (1970-1995) from the Katumani Dryland Research Station. Measured temperatures were available only since 1986, and solar irradiance only for January 1986 to September 1988. Daily GCM rainfall data (1970-1995) are from ECHAM v.4.5 (Roeckner et al., 1996), developed at the Max-Plank Institute (Germany), run at a T42 (approximately $2.8^{\circ}$ ) horizontal resolution, with 18 vertical levels. The ECHAM data were from an ensemble of 24 GCM integrations, each run with different initial atmospheric conditions sampled each year from global observations on different days of the forecast month, but the same observed sea surface temperature (SST) boundary conditions. Although the output of ECHAM simulated with concurrent observed SSTs served the purpose of the present study, the results likely overstate the predictability obtainable under operational conditions where forecast SSTs must be used for any future seasonal forecast period (Goddard and Mason, 2002).

While our objectives focus on rainfall, temperature and solar irradiance also influence crop growth and development, and can confound the effects of rainfall prediction if they are not handled in a consistent manner across scenarios. Yet the frequency of rainfall influences daily temperatures and solar irradiance. For both the observed and corrected GCM rainfall scenarios, we replaced observed daily temperatures and solar irradiance with their long-term monthly mean values conditioned on the occurrence of rainfall as daily input to the crop simulations. We did this to minimize confounding influences while preserving consistency between rainfall frequency and mean temperature and solar irradiance and of temperatures and solar irradiance. Although the procedure artificially reduces the variability of daily temperature and solar irradiance, the impact on simulated yields should be minor, as maize yield response is only weakly nonlinear with respect to temperatures in the broad optimum range, and with respect to solar irradiance.

\subsection{Crop simulations}

We used CERES-Maize version 3.5 (Ritchie et al., 1998) to simulate maize yield response to weather inputs. Soil properties, characteristics of the shortseason cultivar, 'Katumani composite B' and representative management assumptions were based on a previous study at the same site (Keating et al., 1992). The sandy clay loam soil (Chromic Luvisols by the FAO/UNSCO classification) has plant-extractable water-holding capacity of $234 \mathrm{~mm}$ over its $130 \mathrm{~cm}$ depth. For each simulation year, the water balance was initialized on 17 October with soil water at $20 \%$ of capacity. Sowing was simulated the first time soil water content exceeded $40 \%$ of capacity averaged over the top $15 \mathrm{~cm}$ depth, or on 1 November if the threshold soil water content was not met. The simulations assumed a stand density of 4.4 plants $\mathrm{m}^{-2}$, with a $50 \mathrm{~cm}$ inter-row spacing, and $20 \mathrm{~kg} \mathrm{Nha}^{-1}$ applied as ammonium nitrate at planting.

CERES-Maize was run with observed daily rainfall; and with daily rainfall from ECHAM without correction, with the simultaneous correction of frequency and intensity using both a GG and EG transformation, and a multiplicative shift to correct monthly mean rainfall. Yields for individual years were averaged across the 24 available GCM realizations.

\subsection{Analyses}

Due to lack of availability of observed crop yield time series, our evaluation focuses on the ability of the crop model using corrected GCM rainfall to predict yields simulated with observed daily weather, and not on its ability to predict observed yields. We used standard goodness-of-fit statistics on the bias-corrected rainfall and predicted yields. According to Willmott (1982), the mean squared error:

$\mathrm{MSE}=\frac{1}{n} \sum_{i=1}^{n}\left(\hat{y}_{i}-y_{i}\right)^{2}$,

is decomposed into a random component not correctable by linear transformation,

$\mathrm{MSE}_{\mathrm{R}}=\frac{1}{n} \sum_{i=1}^{n}\left(\hat{y}_{i}-y_{i}\right)^{2}$,

and a systematic component that can be corrected by linear regression,

$\mathrm{MSE}_{\mathrm{S}}=\mathrm{MSE}-\mathrm{MSE}_{\mathrm{R}}$,

where $n$ is the number of years $i, y$ and $\hat{y}$ are yields simulated with observed and corrected GCM rainfall, $\hat{y}^{*}$ is $\hat{y}$ calibrated by linear regression. We also used correlation coefficient $(R)$, mean bias error (MBE), root-mean-squared error (RMSE) and index of agreement $d$-statistics Eq. (9):

$d=1-\frac{\sum_{i=1}^{n}\left(\hat{y}-y_{i}\right)^{2}}{\sum_{i=1}^{n}\left(|\hat{y}-\bar{y}|+\left|y_{i}-\bar{y}\right|\right)^{2}}$. 
Willmott (1982) proposed the d statistic as a relatively robust unitless measure of model agreement that accounts for both systematic and random errors.

\section{Results and discussion}

\subsection{Rainfall}

The ECHAM climate model under-predicts the mean monthly rainfall observed at Katumani during the wet seasons and tends to overestimate rainfall during the dry season (Fig. 1a). The negative mean bias, relative to observations at Katumani, is particularly strong during the October-December "short rains" season. It also tends to under-predict year-to-year variability, particularly during the wet seasons (not shown). As expected, the GCM simulated too many rainfall events, with mean intensity too low relative to observations at Katumani (Fig. 1b,c).
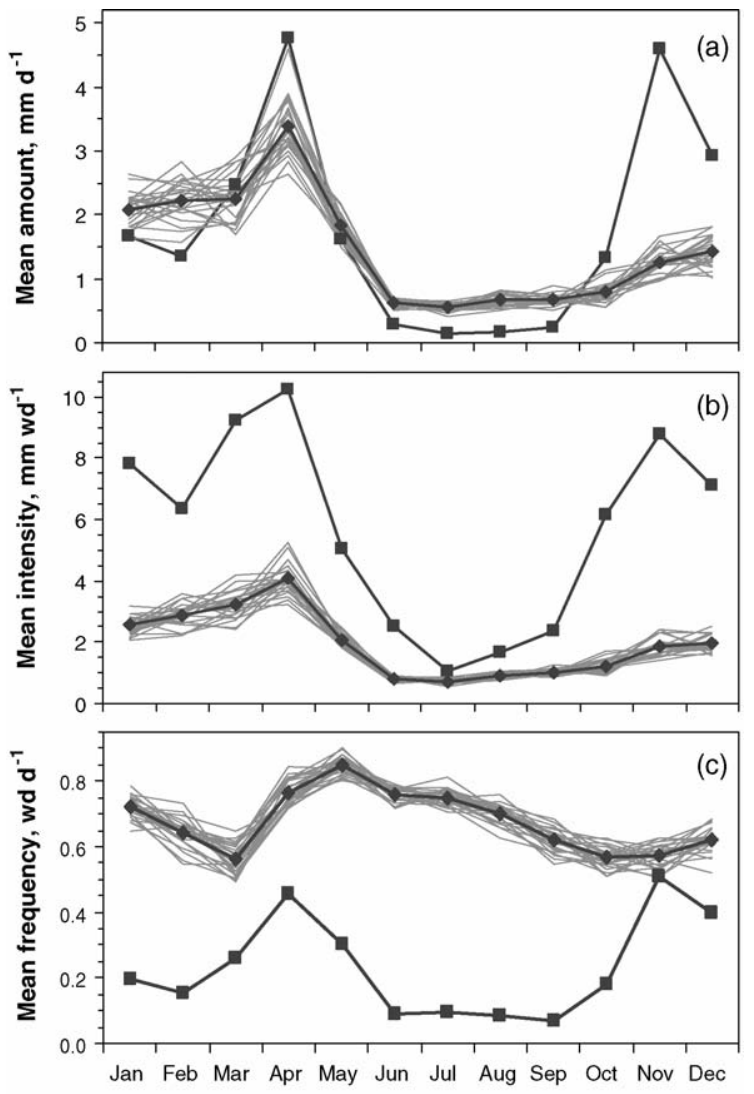

Month

observed

GCM mean

— individual GCM run

Fig. 1. Mean monthly rainfall (a) cumulative amount, (b) intensity and (c) frequency from GCM (ensemble mean and 24 individual realizations) and observations for 25 years at Katumani, Kenya.
The simultaneous bias correction reduced biases of both the first (Fig. 2a-c) and second moments (Fig. 2df) of GCM rainfall relative to observations at Katumani. However, calibration, using either combination of distribution models, underestimated the observed rainfall frequencies slightly, particularly during the wet months. This appears to be due to the presence of many daily GCM rainfall amounts that equal the calibrated threshold values within the $0.1 \mathrm{~mm}$ precision of the records used in the calibration. When this is the case, rejecting every $x_{i, \mathrm{GCM}} \leq \tilde{x}_{\mathrm{GCM}}$ can retain a smaller proportion of GCM rainfall data than the observed rainfall frequency. Corrected rainfall intensity tended to underestimate the historical values slightly (Fig. 2, Table 1). The effect was more pronounced with the GG transformation. The gamma distribution is known to under-represent extreme rainfall events (Wilks, 1999). Furthermore, bias of maximum likelihood estimates of parameters of skewed distributions (e.g., Firth, 1993) can contribute to biased estimates of moments of the distribution. The simultaneous bias correction procedure corrected mean bias (MBE) of GCM rainfall during the October-December rainy season (Table 1). The form of intensity transformation had little impact on mean rainfall amount. Although the simultaneous bias correction aims to correct only systematic error in GCM rainfall, random error during the OctoberDecember season was reduced slightly after the corrections (Table 1).

The simpler multiplicative shift eliminated bias of mean monthly GCM rainfall (Fig. 2a), but left substantial biases of intensity (Fig. 2b) and frequency, particularly for the dryer months (Fig. 2c). As expected, the adjustment changed the mean intensity of GCM rainfall (Fig. 2b). Since the shift modifies only the amount on each day with non-zero rainfall, its impact on rainfall frequency during the dry months (Fig. 2c) was not anticipated. Since the GCM overestimates rainfall during the dry season, the rescaling reduced a substantial number of daily GCM rainfall amounts below the $0.1 \mathrm{~mm}$ threshold for rainfall occurrence. The multiplicative shift also failed to correct the year-toyear variability of GCM rainfall totals and mean intensity (Fig. 2d and e). The new simultaneous bias correction is clearly desirable for applications of daily GCM rainfall that are sensitive to frequency and intensity of rainfall events, or to the interannual variability of rainfall totals.

Because it is designed to correct mean rainfall bias, the simple multiplicative rescaling procedure outperformed the EG and GG transformation in correcting October-December mean rainfall (Table 1). It did not 


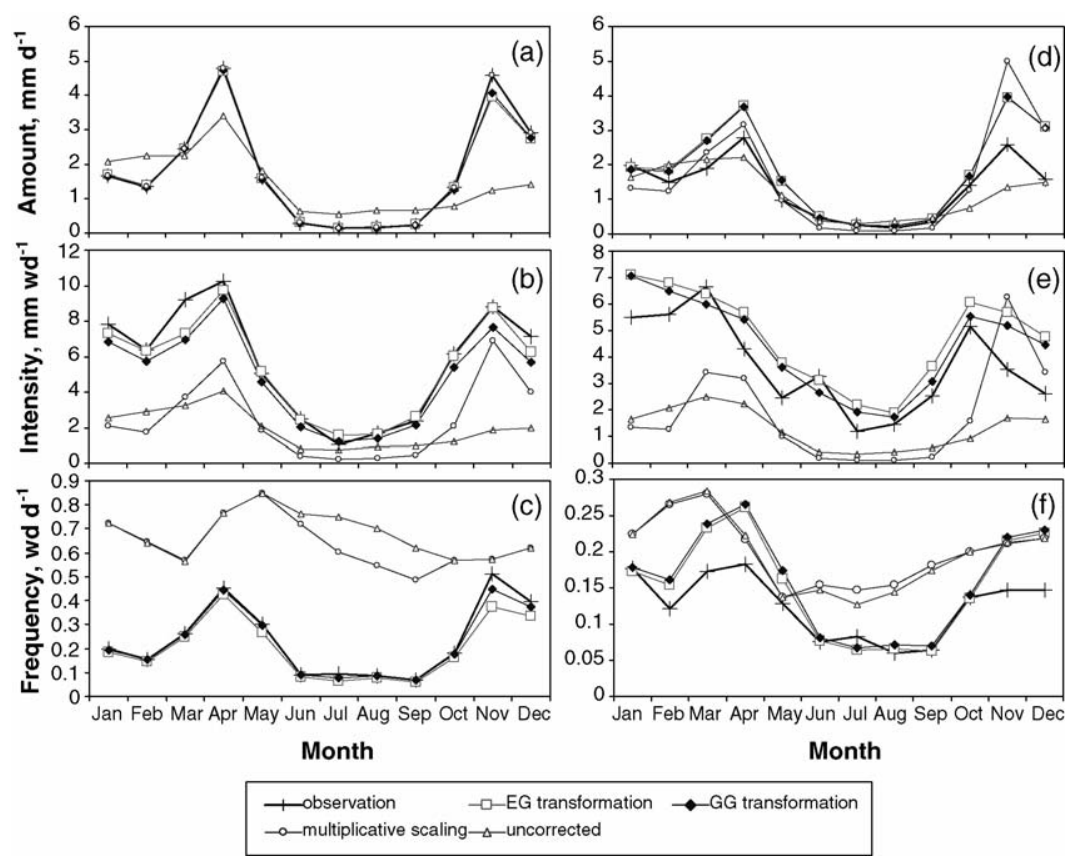

Fig. 2. Interannual mean (a-c) and standard deviation (d-f) of monthly GCM rainfall (a, d) cumulative amount, (b, e) intensity, and (c, f) frequency using the proposed GCM bias correction and multiplicative rescaling.

eliminate mean intensity bias. Yet it produced nearly the same random error for mean intensity and total rainfall as the two versions of the simultaneous bias correction. It had no effect on rainfall frequency for the OctoberDecember season, although it did during the preceding June-September dry season (Fig. 2b).
For October-December mean intensity, the simultaneous correction using the EG transformation gave the best overall fit with observations, based on MSE and $d$ (Table 1). By the same criteria, the GG transformation performed best for correcting frequency, while the simple rescaling procedure gave the best result for

Table 1

Performance of the proposed bias correction on seasonal rainfall statistics (October-december)

\begin{tabular}{|c|c|c|c|c|c|c|}
\hline Method & $R$ & $\operatorname{MBE}\left(\mathrm{mm} \mathrm{wd}^{-1}\right)$ & $d$ & $\operatorname{MSE}\left(\mathrm{mm} \mathrm{wd}^{-1}\right)^{2}$ & $\operatorname{MSE}_{\mathrm{R}}\left(\mathrm{mm} \mathrm{wd}^{-1}\right)^{2}$ & $\operatorname{MSE}_{\mathrm{S}}\left(\mathrm{mm} \mathrm{wd}^{-1}\right)^{2}$ \\
\hline \multicolumn{7}{|l|}{$\mu_{\mathrm{I}}$} \\
\hline EG & 0.429 & -0.318 & 0.643 & 4.279 & 3.649 & 0.629 \\
\hline GG & 0.428 & -1.089 & 0.536 & 5.226 & 3.656 & 1.570 \\
\hline Multiplicative & 0.463 & -2.992 & -0.282 & 12.547 & 3.515 & 9.032 \\
\hline Uncorrected & 0.411 & -5.659 & -4.925 & 35.893 & 3.719 & 32.174 \\
\hline Method & $R$ & MBE (wd d $\left.{ }^{-1}\right)$ & $d$ & $\operatorname{MSE}\left(\mathrm{wd} \mathrm{d}^{-1}\right)^{2}$ & $\operatorname{MSE}_{\mathrm{R}}\left(\mathrm{wd} \mathrm{d}^{-1}\right)^{2}$ & $\operatorname{MSE}_{S}\left(w_{d d^{-1}}\right)^{2}$ \\
\hline \multicolumn{7}{|l|}{$\pi$} \\
\hline EG & 0.733 & -0.074 & 0.619 & 0.011 & 0.006 & 0.006 \\
\hline GG & 0.736 & -0.031 & 0.776 & 0.007 & 0.006 & 0.001 \\
\hline Multiplicative & 0.689 & 0.223 & -0.826 & 0.056 & 0.007 & 0.050 \\
\hline Uncorrected & 0.689 & 0.223 & -0.824 & 0.056 & 0.007 & 0.050 \\
\hline Method & $R$ & $\operatorname{MBE}\left(\mathrm{mm} \mathrm{d}^{-1}\right)$ & $d$ & $\operatorname{MSE}\left(\mathrm{mm} \mathrm{d}^{-1}\right)^{2}$ & $\mathrm{MSE}_{\mathrm{R}}\left(\mathrm{mm} \mathrm{d}^{-1}\right)^{2}$ & $\operatorname{MSE}_{\mathrm{S}}\left(\mathrm{mm} \mathrm{d}^{-1}\right)^{2}$ \\
\hline \multicolumn{7}{|l|}{$\overline{\bar{X}}$} \\
\hline EG & 0.734 & -0.282 & 0.828 & 0.862 & 0.746 & 0.116 \\
\hline GG & 0.735 & -0.257 & 0.831 & 0.850 & 0.744 & 0.106 \\
\hline Multiplicative & 0.756 & -0.0003 & 0.862 & 0.773 & 0.694 & 0.079 \\
\hline Uncorrected & 0.699 & -1.799 & -0.596 & 4.245 & 0.827 & 3.418 \\
\hline
\end{tabular}



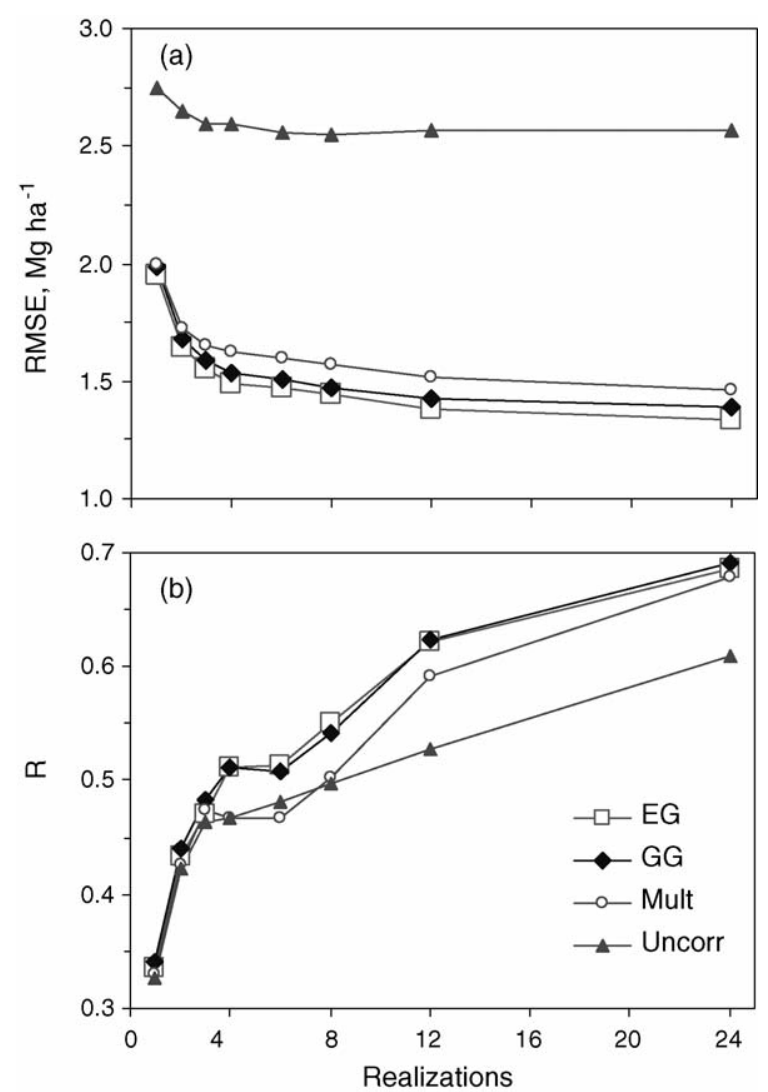

Fig. 3. Sensitivity of (a) root mean squared error (RMSE) and (b) correlations of predicted yields to the number of GCM ensemble members averaged.

seasonal mean rainfall. It is interesting to note that, for the October-December rainy season, most of the error in monthly statistics of the raw daily GCM rainfall is systematic, and therefore readily corrected.

\subsection{Simulated yields}

All of the bias correction procedures clearly improved maize yield simulations (Fig. 3, Table 2). Yet despite substantial under-prediction of mean yields, the correlation of yields simulated with observed and with uncorrected daily GCM rainfall was fairly high, and improved little following bias correction.
This suggests that at least the direction of CERESMaize response to variations in cumulative rainfall amount was fairly insensitive to either mean bias or to the day-to-day variability of rainfall. Although this is consistent with the results of Mavromatis and Jones (1999), we do not anticipate that this will hold true in all contexts. In their analysis of the impact of stochastic disaggregation of observed monthly rainfall, Hansen and Ines (2005) found that maize simulations at two sites in the southeastern USA were much more sensitive to loss of information about daily variability than were simulations at Katumani, Kenya. The prediction skill of the climate model was high during the maize growing season, particularly during November (Fig. 4).

The yields simulated using corrected daily output of the $24 \mathrm{GCM}$ ensemble members were sampled without replacement, and averaged among groups of 1-4, 6, 8, 12 and 24 realizations of GCM rainfall. Predictability of simulated yields improved as the number of ensemble members used increased (Fig. 3). We expect that this improvement would behave asymptotically with larger numbers of GCM runs. Hansen and Ines (2005) observed similar response to sample size when averaging among realizations of stochastically disaggregated monthly rainfall observations or predictions.

The proposed simultaneous bias correction procedure performed better than the uncorrected GCM scenario based on all goodness-of-fit measures, and outperformed simple rescaling in terms of total and systematic error (Table 2, Fig. 5). The GG transformation performed slightly better in improving the random error of yield simulations while EG transformation was more effective at reduced systematic error. However, random error was too similar to support any clear ranking of the three bias correction methods.

\subsection{Understanding yield under-prediction}

In Fig. 5, the gap between the simulated yields using uncorrected GCM rainfall and the three forms of bias corrections is primarily a result of the GCM's bias in simulating monthly rainfall amounts. The reason for the gap between the simulated yields using observed and

Table 2

Performance of the proposed GCM bias correction on yield prediction

\begin{tabular}{lllllll}
\hline Method & $R$ & MBE $\left(\mathrm{Mg} \mathrm{ha}^{-1}\right)$ & $d$ & MSE $\left(\mathrm{Mg} \mathrm{ha}^{-1}\right)^{2}$ & $\mathrm{MSE}_{\mathrm{R}}\left(\mathrm{Mg} \mathrm{ha}^{-1}\right)^{2}$ & $\mathrm{MSE}_{\mathrm{S}}\left(\mathrm{Mg} \mathrm{ha}^{-1}\right)^{2}$ \\
\hline EG & 0.685 & -0.933 & 0.548 & 1.776 & 0.895 & 0.881 \\
GG & 0.691 & -1.015 & 0.510 & 1.923 & 0.881 & 1.043 \\
Multiplicative & 0.678 & -1.095 & 0.433 & 2.128 & 0.909 & 1.218 \\
Uncorrected & 0.610 & -2.346 & -1.135 & 6.595 & 1.058 & 5.537 \\
\hline
\end{tabular}



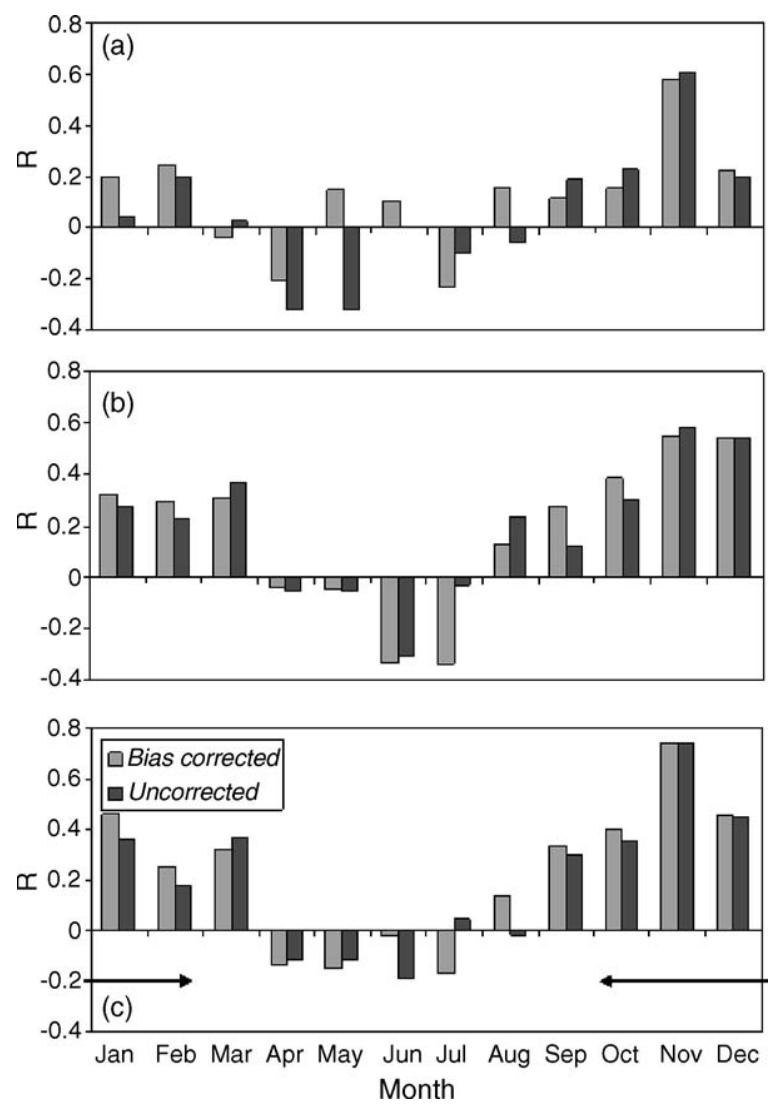

Fig. 4. Correlations between monthly (a) intensity, (b) frequency and (c) amount observed at Katumani and simulated by the GCM. The arrows show the maize growing season.

bias-corrected daily GCM rainfall is not as obvious. Visual inspection of observed and corrected GCM time series from 1992 and 1999 (not shown) suggests that the GCM may simulate rainfall events with stronger time dependency, or clustering, than observed at the Katumani station. The correction procedure cannot correct for any biases in autocorrelation of rainfall occurrence or intensities. Fig. 6 shows the cumulative

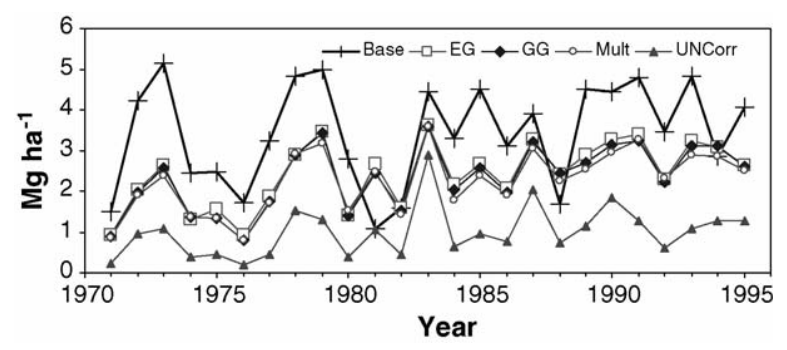

Fig. 5. Simulated maize yields using observed daily rainfall, uncorrected GCM rainfall, the proposed bias corrections and multiplicative rescaling.

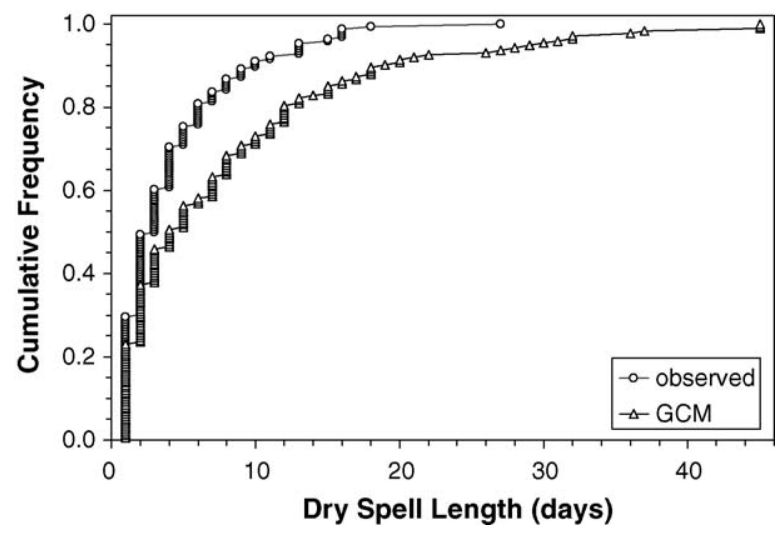

Fig. 6. Cumulative relative frequency of dry spell lengths observed and from the first two members of GG-corrected GCM simulations, 15 November-31 December.

frequency distribution of dry spell lengths, defined as days with $<1.0 \mathrm{~mm}$ of precipitation, for observations and the first two members of GG-corrected GCM rainfall, for 15 November-31 December, through the entire 1970-1995 record. The average dry spell length from the corrected GCM simulations ( 8,18 days) is roughly double the observed average (4.20 days). Dry spells simulated by the GCM tend to be longer than observed. Therefore, for a rainfall given frequency and seasonal total, the corrected daily GCM produces more dry spells that are sufficiently long to deplete stored soil water, leading to water stress and reduced yield, than observed. Interaction between the variability in simulated water availability across the $24 \mathrm{GCM}$ realizations, and the nonlinear and generally concave yield response of crops to water variability may also contribute to the under-prediction of yields. Hansen and Ines (2005) found that variability in seasonal total rainfall among realizations of rainfall from a stochastic weather generator resulted in similar negative mean bias of simulated yields. In operational forecast mode, this yield bias can be corrected by linear regression.

\section{Summary and conclusions}

We present a method that can be used to transform daily rainfall simulated by a GCM to make it more suitable for use with crop simulation models. Because GCMs show substantial biases in total amount, frequency and intensity of rainfall, we sought to correct amount by correcting mean frequency and the intensity distribution of GCM rainfall. Mean monthly frequency is corrected by calibrating a threshold from the empirical distribution of historical data, then truncating the empirical distribution of daily GCM rainfall at that 
threshold. The truncated daily GCM rainfall is then mapped onto a fitted distribution observed rainfall intensities. Since rainfall amount is equal to the product of rainfall intensity and frequency, correcting these two rainfall components also corrects total rainfall amount.

The correction procedure improved the overall predictability of yields. Most of the improvement from correcting GCM rainfall was due to reducing mean bias. Yet maize yields simulated with GCM rainfall corrected using a simpler multiplicative shift performed almost as well as results using the proposed frequency-intensity correction. However, ECHAM model that we evaluated appears to simulate daily rainfall with unrealistic time structure at the study location. This distortion appeared to contribute to substantial systematic under-prediction of maize yields, and cannot be corrected readily.

The question of how much, if any, predictive information GCMs provide about the higher-order variability of "weather within climate" remains to be answered. If GCMs do provide any advance information about variability within the growing season that is relevant to crop response but discarded when averaging into forecast seasonal anomalies, the proposed bias correction provides one potential avenue for incorporating that information into crop simulations. However, its practical utility for yield forecasting at a long leadtime may be limited by the ability of GCMs to simulate rainfall with a realistic time structure.

\section{Acknowledgements}

The authors wish to acknowledge the assistance of Michael Bell in providing daily ECHAM4.5 rainfall data. This work has been supported by the National Oceanic and Atmospheric Administration (NOAA) with grant/ cooperative agreement number NA67GP0299. The views expressed in this paper are those of the authors and do not necessarily reflect the views of NOAA or any of its sub-agencies.

\section{References}

Baron, C., Sultan, B., Balme, M., Sarr, B., Traore, S., Lebel, T., Janicot, S., Dingkuhn, M., 2005. From GCM grid cell to agricultural plot: scale issues affecting modelling of climate impact. Philos. T. Roy. Soc. B. 360, 2095-2108.

Carter, T.R., Parry, M.L., Harasawa, H., Nishioka S., 1994. IPCC technical guidelines for assessing climate change impacts and adaptations. Special Report to Working Group II, Intergovernment Panel on Climate Change, 59 pp.

Challinor, A.J., Slingo, J.M., Wheeler, T.R., Doblas-Reyes, F.J., 2005. Probabilistic simulations of crop yield over western India using DEMETER seasonal hindcasts ensembles. Tellus 57A, 498-512.
Feddersen, H., Andersen, U., 2005. A method for statistical downscaling of seasonal ensemble predictions. Tellus 57A, 398408.

Firth, D., 1993. Bias reduction of maximum likelihood estimates. Biometrika 80, 27-38.

Goddard, L., Mason, S.J., 2002. Sensitivity of seasonal climate forecasts to persisted SST anomalies. Clim. Dyn. 19, 619-632.

Goddard, L., Mason, S.J., Zebiak, S.E., Ropelewski, C.F., Basher, R., Cane, M.A., 2001. Current approaches to seasonal to interannual climate predictions. Int. J. Climatol. 21, 1111-1152.

Hansen, J.W., Indeje, M., 2004. Linking dynamic seasonal climate forecasts with crop simulation for maize yield prediction in semiarid Kenya. Agric. Forest Meteorol. 125, 143-157.

Hansen, J.W., Ines, A.V.M., 2005. Stochastic disaggregation of monthly rainfall data for crop simulation studies. Agric. For. Meteorol. 131, 233-246.

Hansen, J.W., Jones, J.W., 2000. Scaling-up crop models for climate variability applications. Agric. Syst. 65, 43-72.

Indeje, M., Semazzi, F.H.M., Ogallo, L.J., 2000. ENSO signals in East African rainfall and their prediction potentials. Int. J. Climatol. 20, $19-46$.

Keating, B.A., Wafula, B.M., Watiki, J.M., 1992. Exploring strategies for increased productivity - the case for maize in semi-arid Eastern Kenya. In: Probert, M.E. (Ed.), A Search for Strategies for Sustainable Dryland Cropping in Semi-arid Eastern Kenya. ACIAR Proceedings No. 41. Australian Centre for International Agricultural Research, Canberra, Australia, pp. 90-101.

Keating, B.A., McCown, R.L., Wafula, B.M., 1993. Adjustment of nitrogen inputs in response to a seasonal forecast in a region of high climatic risk. In: Penning de Vries, F.W.T., Teng, P., Metselaar, K. (Eds.), Systems Approaches for Agricultural Development, Vol. 2. Kluwer Academic Publishers, Dordrecht, The Netherlands, pp. 233-252.

Law, A.M., Kelton, W.D., 1982. Simulation Modeling and Analysis. McGraw-Hill Book Co., USA, p. 400.

Mavromatis, T., Jones, P.D., 1999. Evaluation of HADCM2 and direct use of daily GCM data in impact assessment studies. Clim. Change. 41, 583-614.

Mearns, L.O., Schneider, S.H., Thompson, S.L., McDaniel, L.R., 1990. Analysis of climate variability in general circulation models: comparison with observations and changes in variability in $2 \times \mathrm{CO}_{2}$ experiments. J. Geophys. Res. D95, 20469-20490.

Mearns, L.O., Giorgi, F., McDaniel, L., Shields, C., 1995. Analysis of daily variability of precipitation in a nested regional climate model: comparison with observations and doubled $\mathrm{CO}_{2}$ results. Global. Planet. Change 10, 55-78.

Mearns, L.O., Rosenzweig, C., Goldberg, R., 1996. The effects of changes in daily and interannual climatic variability on CERESWheat: a sensitivity study. Clim. Change 32, 257-292.

Mutai, C.C., Ward, M.N., Coleman, A.W., 1998. Towards the prediction of the East Africa short rains based on sea-surface temperature-atmosphere coupling. Int. J. Climatol. 18, 975-997.

Probert, M.E. (Ed.), 1992. A search for strategies for sustainable dryland cropping in Semi-arid Eastern Kenya. ACIAR Proceedings No. 41. Australian Centre for International Agricultural Research, Canberra, Australia.

Riha, S.J., Wilks, D.S., Simeons, P., 1996. Impacts of temperature and precipitation variability on crop model predictions. Clim. Change 32, 293-311.

Ritchie, J.T., Singh, U., Godwin, D.C., Bowen, W.T., 1998. Cereal growth, development and yield. In: Tsuji, G.Y., Hoogenboom, G., Thornton, P.K. (Eds.), Understanding Options for Agricul- 
tural Production. Kluwer Academic Publishers, Dordrecht, The Netherlands, pp. 79-98.

Roeckner, E., Arpe, K., Bengtsson, L., Claussen, C.M., Dümenil,L., Esch, M., Giorgetta, M., Schiese, U., Schulzweida, U., 1996. The atmospheric general circulation model ECHAM-4: model description and simulation of present-day climate. MaxPlanck-Institute for Meteorology. Report No. 218, Hamburg, Germany.

Wilby, R.L., Wigley, T.M.L., 1997. Downscaling general circulation model output: a review of methods and limitations. Prog. Phys. Geogr. 21, 530-548.

Wilby, R.L., Wigley, T.M.L., Conway, D., Jones, P.D., Hewitson, B.C., Main, J., Wilks, D.S., 1998. Statistical downscaling of general circulation model output: a comparison of methods. Water Resour. Res. 34, 2995-3008.

Wilks, D.S., 1999. Interannual variability and extreme-value characteristics of several stochastic daily precipitation models. Agric. For. Meteorol. 93, 153-169.

Wilks, D.S., 2002. Realizations of daily weather in forecast seasonal climate. J. Hydrometeorol. 3, 195-207.

Willmott, C.J., 1982. Some comments on the evaluation of model performance. Bull. Am. Meteorol. Soc. 63, 1309-1313.

Wood, A.W., Maurer, E.P., Kumar, A., Lettenmaier, D.P., 2002. Longrange experimental hydrologic forecasting for the eastern United States. J. Geophys. Res. 107 (D20), 4429, doi:10.1029/ 2001JD000659. 